\title{
Validation of nursing outcome indicators of the nursing outcomes classification: dry eye severity
}

\author{
Validação de indicadores do resultado de enfermagem da Nursing Outcomes classification: gravidade do olho seco
}

Validación de indicadores del resultado de enfermería de la Nursing Outcomes classification: gravedad del ojo seco

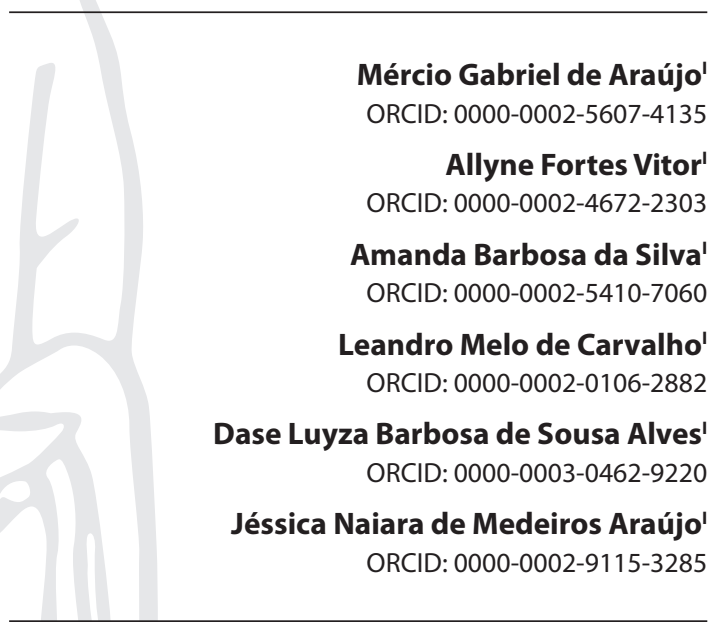

'Universidade Federal do Rio Grande do Norte. Natal, Rio Grande do Norte, Brazil.

How to cite this article: Araújo MG, Vitor AF, Silva AB, Carvalho LM, Alves DLBS, Araújo JNM. Validation of nursing outcome indicators of the nursing outcomes classification: dry eye severity. Rev Bras Enferm. 2020;73(Suppl 5):e20190854 doi: http://dx.doi.org/10.1590/0034-7167-2019-0854

Corresponding author: Mércio Gabriel de Araújo E-mail: mercio_gabriel@hotmail.com

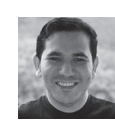

EDITOR IN CHIEF: Antonio José de Almeida Filho ASSOCIATE EDITOR: Ana Fátima Fernandes

Submission: $03-16-2020$

Approval: 05-26-2020

\section{ABSTRACT}

Objective: To validate the content of the indicators of the nursing outcome Dry eye severity, of the Nursing Outcomes Classification, in adult patients admitted to the intensive care unit. Methods: Methodological study of content validity, developed in two stages: the first, consisting of 23 specialists; and the second, of a consensus group formed by ten nurses. For analyzing the data in the first stage, we used the content validity index and binomial test for each indicator; in the second stage, the discussions of each meeting were transcripted, and the indicators that achieved $100 \%$ consensus were validated. Results: Of the 14 indicators evaluated by the specialists, 7 presented a cut-off point below 0.80 , but did not show statistical significance in the binomial test. In the consensus group's validation, six indicators were reformulated. Conclusion: This study considered the 14 indicators valid for evaluating patients admitted to the intensive care unit.

Descriptors: Validation Studies; Dry Eye Syndromes; Nursing Evaluation; Nursing; Intensive Care Unit.

\section{RESUMO}

Objetivo: Validar o conteúdo dos indicadores do resultado de enfermagem Gravidade do olho seco, da Nursing Outcomes Classification, em pacientes adultos internados em unidade de terapia intensiva. Métodos: Estudo metodológico de validação de conteúdo, desenvolvido em duas etapas: a primeira, composta por 23 especialistas; e a segunda, por um grupo-consenso formado por 10 enfermeiros. Para análise dos dados da primeira etapa, utilizou-se o índice de validade de conteúdo e teste binominal para cada indicador; na segunda etapa, ocorreu transcrição das discussões de cada encontro, e os indicadores que obtiveram consenso $100 \%$ foram validados. Resultados: Dos 14 indicadores avaliados pelos especialistas, 7 apresentaram ponte de corte inferior a 0,80 , mas não evidenciaram significância estatística pelo teste binomial. Na validação por grupo-consenso, seis indicadores foram reformulados. Conclusão: Os 14 indicadores foram considerados válidos para serem utilizados na avaliação de pacientes internados em unidade de terapia intensiva.

Descritores: Estudos de Validação; Síndromes do Olho Seco; Avaliação em Enfermagem: Enfermagem; Unidade de Terapia Intensiva.

\section{RESUMEN}

Objetivo: Validar el contenido de los indicadores del resultado de enfermería Gravedad del ojo seco, de la Nursing Outcomes Classification, en pacientes adultos internados en unidad de terapia intensiva. Métodos: Estudio metodológico de validación de contenido, desarrollado en dos etapas: la primera, compuesta por 23 especialistas; y la segunda, por un consenso en equipo formado por 10 enfermeros. Para análisis de los datos de la primera etapa, ocurrió transcripción de las discusiones de cada encuentro, y los indicadores que obtuvieron consenso $100 \%$ han sido validados. Resultados: De los 14 indicadores evaluados por los especialistas, 7 presentaron puente de cohorte inferior a 0,80 , pero no evidenciaron significación estadística por él es binominal. En la validación por consenso en equipo, seis indicadores han sido reformulados. Conclusión: Los 14 indicadores han sido considerados válidos para ser utilizados en la evaluación de pacientes internados en unidad de terapia. Descriptores: Estudio de Validación; Síndrome del Ojo Seco; Evaluación en Enfermería; Enfermería; Unidad de Terapia Intensiva. 


\section{INTRODUCTION}

Dry eye syndrome, keratoconjunctivitis sicca, or dysfunctional tear syndrome is a multifactorial condition of the tear film and the ocular surface predisposing to discomfort, visual disturbances, and instability of the structure, with possible damage to the surface of the eye. The dry eye in the Intensive Care Unit (ICU) can hinder and obstruct the mechanism of eye protection and trigger eye damage ${ }^{(1)}$.

One of the contexts that predispose to the development of the dry eye is the ICU. A study relating dry eye syndrome to ICU points to this clinical condition as the ocular condition with the highest incidence $(53 \%)$ in this environment ${ }^{(2)}$. Besides, ocular dryness was evident in $43.2 \%$ of the eyes evaluated in a crosssectional study conducted in northeastern Brazil ${ }^{(3)}$.

One of the main complications for the development of the dry eye in the ICU is or incomplete eyelid closure due to the use of sedatives and coma ${ }^{(3-4)}$. Therefore, it is necessary to develop eye care based on concrete actions to improve patients' health conditions in the ICU and prevent eye problems.

The nurse must provide comprehensive care to avoid any unwanted events regarding the integrity of the patient's health. In this sense, team members should carry out the evaluation and eye care of this patient periodically and continuously according to the need. This action requires this professional's methodological basis for giving the team a uniform method and language to evaluate, plan, and perform care that promotes eye health. This organization is made possible by the nursing process (NP) associated with classification systems ${ }^{(5)}$.

The NP is methodologically organized in five stages (history, diagnosis, planning, implementation, and evaluation) and has classification systems to standardize the language, which can be related to nursing diagnoses - NANDA International (NANDA-I), nursing interventions - Nursing Intervention Classification (NIC) and nursing outcomes - Nursing Outcomes Classification (NOC).

The use of taxonomies such as NANDA-I, NIC, and NOC issues communication among nurses as they show a clear, standardized, and comprehensive approach to the components related to nursing diagnoses, interventions, and outcomes. Therefore, the use of these taxonomies favors a refined clinical work process when used, mainly, in care practice. Therefore, it is essential to develop research that contributes to the improvement of the nursing practice, especially on the use of taxonomies, whose demand encompasses the refinement of the components of nursing diagnoses, interventions, and outcomes, thus allowing the production of information that collaborates nurses' care.

In this context, this study focuses on the nursing outcome (NO) 2110 - Dry Eye Severity, defined as "severity of signs and symptoms of insufficiency of tears" and includes the following indicators: 211001 - Decrease in tear production; 211002 - Incomplete eyelid closure; 211003 - Burning eye sensation; 211004 - Redness of the conjunctiva; 211005 - Itchy eye sensation; 211006 - Gritty sensation; 211007 - Foreign body sensation; 211008 - Eye pain; 211009 - Excessive watering; 211010 - Blurred vision; 211011 Excess mucous secretions; 211012 - Sensitivity to light ${ }^{(6)}$.

The indicators presented by the NOC taxonomy for each NO help nurses in evaluating and defining patients' health status, provide a uniform mass of nursing data to support decisions, and contribute to the improvement of the nursing set of knowledge. Such indicators are measured by a Likert scale that ranges from the most more impaired value (1) to a non-impaired one (5), and the results determine a baseline measure or measure of the nursing intervention performed ${ }^{(6)}$.

Therefore, validating NO m contributes to improving the clinical nursing practice, allowing its development as a science, since it represents the endorsement of a particular phenomenon based on obtaining useful elements for its characterization. It can also guide nurses' clinical practice; assist in identifying a NO; strengthen the NP and reduce the distances between taxonomy and nursing care through more accessible language.

The need to make the NR accurate justifies this study by allowing a more stable and reliable measure among nurses. Thus, validating the NO Dry Eye Severity indicators may contribute to improving nursing care by reducing problems without scientific evidence and goals not consistent with the formulated diagnoses.

\section{OBJECTIVE}

To validate the content of the indicators of the nursing outcome Dryeye severity, of the Nursing Outcomes Classification, in adult patients admitted to the intensive care unit.

\section{METHODS}

\section{Ethical aspects}

This study is part of a macro project entitled "Validation of the nursing outcome Dryeye Severity in adult patients admitted to the intensive care unit," which was approved by the Research Ethics Committee of the Universidade Federal do Rio Grande do Norte (CEP/UFRN). The research included the participants signed the Free and Informed Consent Form and followed the recommendations of Resolution 466/12 of the National Health Council.

\section{Design, period and place of study}

A methodological study on content validation of the nursing outcome Dry eye Severity, belonging to the NOC taxonomy, developed at the Nursing Department at UFRN, from September 2017 until May 2018. Psychometric evaluation was used as an operational method $^{(7)}$. For this, the content validation was carried out in two phases: (i) by specialists; and (ii) by consensus group.

\section{Population or sample; criteria of inclusion and exclusion}

In order to search for and select nurses able to participate, we used an adaptation of the scoring system or criteria for the definition of expertise ${ }^{(8)}$, in which the criterion "master in nursing" was adopted as the standard minimum. The population for content validation consisted of specialists identified by the snowball sampling, including indications from professionals; and through searching the Lattes Platform of the portal of the Conselho Nacional de Desenvolvimento Científico e Tecnológico (CNPq-National Council for Scientific and Technological Development), using the following keywords: "Dry Eye Syndromes," "Intensive Care Unit" and "Nursing Process." 
After this initial identification, the resumes were analyzed considering the academic titles, professional experience, and publications. The following criteria of including specialists were used: being a nurse with a master's or doctorate in the health field; having developed a dissertation or thesis in the areas of eye health, intensive care unit or nursing process; having published articles in the field of eye health between the years 2014 and 2018, corresponding to the last five years. Participants were excluded when papers published in the field of eye health did not identify the year of publication or were unavailable in the databases.

The calculated sample was based on estimating the calculation of the assessments means (CVI) for each element to be analyzed, which was adapted from the proposed calculation for the validation of nursing diagnoses. We considered a confidence level $\left(Z_{1-\alpha / 2}\right)$ of $95 \%$ (1.96), a standard deviation (SD) of 0.17 and a sample error (SE) of 0.07 Thus, when using the formula $\mathrm{n} 0=\left[\left(\mathrm{Z}_{1-\mathrm{a} / 2} . \mathrm{S}\right) / \mathrm{e}\right]^{2}$, the sample totaled 23 judges $^{(9)}$. However, the invitation was sent to 64 specialists, given the difficulty reported in similar studies of having the material returned in a satisfactory period. Thus, 23 specialists responded to the assessment instrument in a comprehensive and timely manner and, therefore, corresponded to the final sample.

For composing the consensus group, the number of participants was adapted from the focal group technique, in which the authors recommend between 6 and 15 participants ${ }^{(10)}$. Thus, we invited ten nurses linked to the research groupNúcleo de Estudos em Pesquisa e Enfermagem Clínica da Universidade Federal do Rio Grande do Norte (NEPEC/UFRN). The nurses from NEPEC/UFRN were contacted to participate due to their experience in validation studies and taxonomies of nursing and, also, eye health. All ten invited nurses agreed to participate and thus composed the final sample of the consensus group.

Also related to the consensus group, the study included nurses having an academic level of at least a master's degree and experience in validation studies and taxonomies of nursing or eye health. As exclusion criteria, we considered nurses who did not participate in at least one group meeting in the year of study. However, there was no sample loss since all invited nurses participated in all scheduled meetings.

\section{Study Protocol}

The indicators and the constitutive definitions, operational and operational magnitude of the nursing outcome, Dry eye Severity of the Nursing Outcomes Classification ${ }^{(6)}$ were built in a previous study based on a concept analysis ${ }^{(11)}$.

In the first phase, the experts were invited to participate in the study through an invitation letter sent by e-mail containing the researcher's identification and clarification about the research objectives. A link was also sent via Google Forms containing the Free and Informed Consent Form (ICF) and the instrument. Thus, those who responded positively had access to the instrument through a form.

The instrument consisted of two parts: the first is related to the specialists' data characterization, and the second part consisted of title, definition, indicators and constitutive definitions, operational and operational magnitude of the nursing outcome Dry eye Severity. Besides, it contained five criteria for evaluating items proposed by psychometry: Behavior, Objectivity, Simplicity,
Relevance, and Accuracy ${ }^{(7)}$. For measuring the responses, a fivepoint Likert scale was used with the following correspondences: 1 - not characteristic; 2 - very uncharacteristic; 3 - fairly characteristic; 4 - considerably characteristic; 5 - very characteristic. Then, a blanket for specialists' suggestions was created to contribute to the validation of the nursing outcome.

In the second phase, with the consensus group, nurses were invited to participate through an invitation letter sent by e-mail, and, for those who responded positively, the Informed Consent Form was sent. This phase aimed at the evaluation, carried out by the consensus group, of recommendations pointed out by the specialists during the evaluation of the instrument in the previous phase, as recommended by the operational method. To this end, four meetings were held, which took place in the research group room of the UFRN Nursing Department, lasting five hours each.

Initially, the authorization term for using voice and a characterization instrument was delivered to the consensus group members. After that, one of the researchers was responsible for the mediation, having the help of a script previously constructed with information from the experts' evaluation. Thus, the material resulting from the first phase was presented to nurses, and their evaluations were transcribed. All suggestions from the group participants were discussed until consensus was reached, after which it is understood that the indicators have consistency, solidity, and applicability in the context of the studied phenomenon. Therefore, the consensus group's objective was to synthesize the experts' suggestions and refine the indicators that showed inferior agreement in some psychometric criteria.

\section{Analysis of results and statistics}

For analysis and organization, the collected data were stored in the program Microsoft Excel for Windows 2010 and, subsequently, submitted to the statistical analysis of the statistical program Statistical Package for the Social Sciences (SPSS), version 22.

For the descriptive analysis of the participants' characterization, the frequencies, measures of the distribution center, and their variability were considered. For verifying the normality of the data, the Shapiro-Wilk test was used.

The Content Validity Index (CVI) was used to analyze the data obtained by specialists. The CVI helps to evaluate the content of the indicators regarding the representativeness of the measure and is considered valid if, when computing the evaluations of the specialists, it obtains an approval index above $80 \%{ }^{(12)}$. Therefore, the indicators were considered inadequate when they obtained scores 1, 2, and 3 and considered adequate when they obtained scores 4 and 5 . For each indicator, the binomial test was applied; thus, it was possible to verify the proportion of specialists who considered it adequate.

The analysis of the data of the consensus group occurred through the recording and subsequent transcription of the discussions of each meeting. The non-conformities resulting from the psychometric criteria for those indicators with CVI values below 0.80 , as well as the suggestions and recommendations pointed out by the specialists, were submitted and analyzed by the group. To this end, each indicator was meticulously read and its respective constitutive definitions, operational and operational magnitude, followed by the experts' suggestions and recommendations. The consensus occurred after 
$100 \%$ approval of the participants present at the meetings. Thus, the indicators that achieved consensus were validated, and, in the end, the NO Dry eye Severity changed this phase.

\section{RESULTS}

In the first phase of content validation, 23 experts participated, who were responsible for evaluating the 12 indicators of the NO Dry eye Severity of the NOC and two new indicators. The suggestions and recommendations proposed by the specialists were transcribed in full and constituted material for the analysis of the group-consensus phase.

Regarding the specialists' profile, we observed that $78.26 \%$ were female, and $65.22 \%$ were up to 35 years old. Regarding the academic degree, $69.57 \%$ were $\mathrm{PhDs}$ and $30.43 \%$ masters. Regarding the length of experience, $60.87 \%$ had up to 10 years. The average age of specialists was 35.35 ( \pm 7.49 ), while the median length of work was 9.00 years.

As seen in Table 2, the "Relevance" and "Behavior" criteria did not show indicators lower than the cut-off point. With regard to "Objectivity," seven indicators showed low CVI values: Burning eye sensation ( 0.74 ), Itchy eye sensation ( 0.70 ), Gritty sensation on the entire ocular surface ( 0.70$)$, Localized Foreign body sensation on the entire ocular surface ( 0.65$)$, Excessive watering( 0.70$)$, Sensitivity to light ( 0.78 ) and eyestrain ( 0.65 ). However, they all had $p>0.05$ as a result of the binomial test and, therefore, could not be excluded in this analysis.

Regarding "Simplicity" criterion, the indicators Itchy eye sensation(0.74), Gritty sensation on the entire ocular surface (0.78), Localized Foreign body sensation on the entire ocular surface $(0,65)$, Excessive watering (0.78) and eyestrain (0.74) obtained a CVI lower than 0.80 . However, as in the previous criterion, all five presented $p>0.05$.

Regarding the "Accuracy" criterion, seven indicators were shown below the cut-off point, namely: Burning eye sensation $(0,74)$, Itchy eye sensation $(0,74)$, Gritty sensation on the entire ocular surface $(0,78)$, Localized Foreign body sensation on the entire ocular surface $(0,74)$, Excessive watering $(0,74)$, Sensitivity to light $(0,78)$ and eyestrain $(0,61)$. However, all also had $p>0.05$.

Also, it is noteworthy: all indicators that showed statistically significant values of $p(p<0.05$ or $p$ $<0.01$ ) among the psychometric criteria referred to CVI greater than 0.80 , being, therefore, admitted.

However, the indicators that showed in any of the CVI psychometric criteria that had a cut-off point below 0.80 were submitted to the consensus group. In addition, together with the evaluation of each indicator, the experts proposed adjustments, which were also submitted to the consensus group.

Regarding the consensus group's constitution, 90\% were female, $70 \%$ had an academic master's degree, and $50 \%$ were postgraduate students holding a doctoral degree. Also, 40\% were university professors, and $40 \%$ were nursing assistants.

In this phase, the critical and pertinent analysis of the consensus group resulted in maintaining eight indicators, seven of which are NOC (burning eye sensation, Redness of the conjunctiva, itchy eye sensation, eye pain, excessive watering, blurred vision and Sensitivity to light) and one new (Eyestrain). Also in reformulating the title of six indicators, five of which are NOC (decreased tear production [tear production], incomplete eyelid closure [eyelid closure], Gritty sensation [Gritty sensation on the entire ocular surface], foreign body sensation [localized foreign body sensation on the entire ocular surface], Excessive mucous secretions [mucous secretion]) and one new (decreased blink mechanism [blinking mechanism]). These results are shown in Chart 1.

Table 1 - Profile of the specialists who composed the first phase of content validation of the nursing result Dry eye Severity, Natal, Rio Grande do Norte, Brazil, $2020(n=23)$

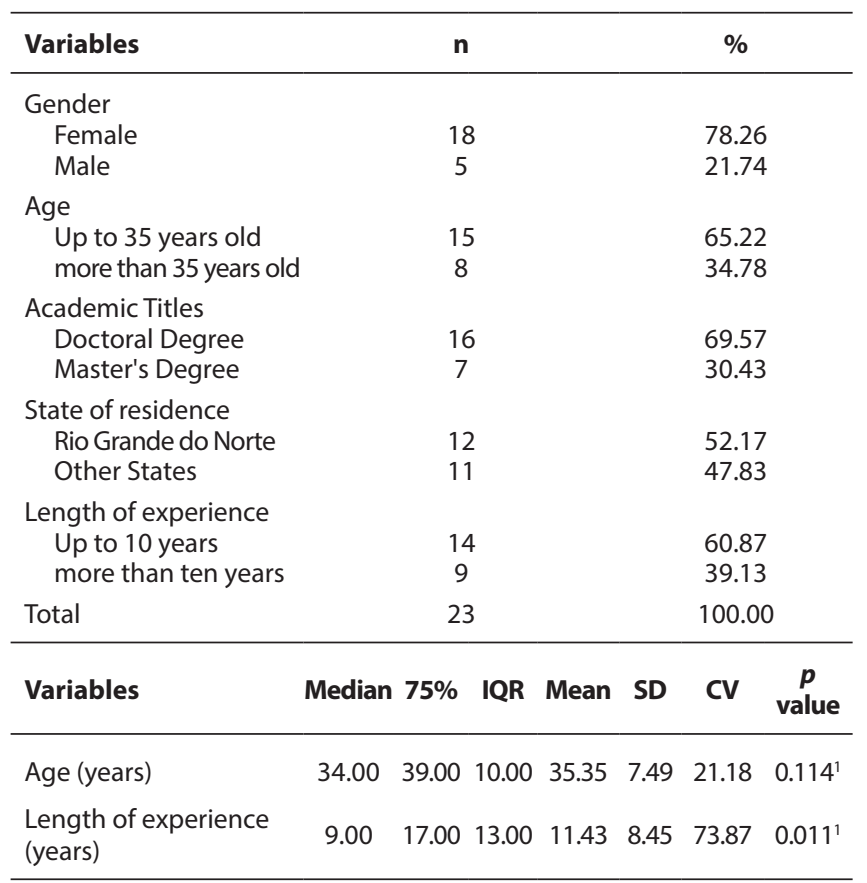

Notes: IQR: interquartile range; SD: standard deviation; CV: coefficient of variation; ${ }^{1}$ Shapiro-Wilk test.

Table 2 - Specialists' evaluation of nursing outcome indicators Dry Eye Severity regarding psychometric criteria Relevance, Behavior, Objectivity, Simplicity and Accuracy, Natal, Rio Grande do Norte, Brazil, 2020 (N = 23)

\begin{tabular}{cccccc}
\hline Indicators & Relevance & Behavior & Objectivity & Simplicity & Accuracy \\
\hline 1 & $0.96^{1}$ & 0.91 & 0.87 & 0.87 & $0.96^{1}$ \\
2 & $0.96^{1}$ & 0.91 & 0.91 & $0.96^{1}$ & $0.96^{1}$ \\
3 & 0.91 & 0.91 & 0.74 & 0.83 & 0.74 \\
4 & $1.00^{2}$ & 0.87 & 0.87 & 0.87 & 0.87 \\
5 & 0.91 & 0.87 & 0.70 & 0.74 & 0.74 \\
6 & $0.96^{1}$ & 0.87 & 0.70 & 0.78 & 0.70 \\
7 & 0.87 & 0.83 & 0.65 & 0.65 & 0.74 \\
8 & $1.00^{2}$ & $0.96^{1}$ & 0.87 & 0.91 & 0.87 \\
9 & 0.83 & 0.87 & 0.70 & 0.78 & 0.74 \\
10 & 0.91 & $0.96^{1}$ & 0.83 & 0.87 & 0.83 \\
11 & $1.00^{2}$ & 0.91 & 0.91 & 0.87 & 0.91 \\
12 & 0.91 & 0.91 & 0.78 & 0.87 & 0.78 \\
13 & 0.91 & 0.83 & 0.65 & 0.74 & 0.61 \\
14 & $0.96^{1}$ & 0.87 & $1.00^{2}$ & 0.91 & 0.91 \\
\hline
\end{tabular}

Notes: ${ }^{1} p$ value $<0.05,{ }^{2} p$ value $<0.01$. 1. Decreased tear production; 2 . Incomplete eyelid closure; 3 . Burning eye sensation; 4 . Redness of the conjunctiva; 5 . Itchy eye sensation; 6 . Gritty sensation; 7. Foreign body sensation Eye pain; 9. Excessive watering; 10. Blurred vision; 11. Excessive mucous secretions; 12. Sensitivity to light; 13. Eyestrain; 14. Decreased blink mechanism. 
Chart 1 - Summary of the results of the consensus group for the nursing outcome Dry Eye Severity

\begin{tabular}{|l|l|}
\hline Indicators & Results \\
\hline Maintained & $\begin{array}{l}\text { Burning eye sensation } \\
\text { Redness of the conjunctiva } \\
\text { Itchy eye sensation } \\
\text { Eye pain } \\
\text { Excessive watering } \\
\text { Blurred vision } \\
\text { Sensitivity to light } \\
\text { Eyestrain - New }\end{array}$ \\
\hline Reformulated & $\begin{array}{l}\text { Decreased tear production (tear production) } \\
\text { Incomplete eyelid closure (Eyelid closure) }\end{array}$ \\
& $\begin{array}{l}\text { Gritty sensation (Gritty sensation sandy on the entire } \\
\text { ocular surface) } \\
\text { Foreign body sensation (Localized foreign body sensation } \\
\text { on the entire ocular surface) } \\
\text { Excessive mucous secretions (mucous secretion) } \\
\text { Decreased blink mechanism (blinking mechanism) - New }\end{array}$ \\
\hline
\end{tabular}

It is also noteworthy, although the indicators Decreased tear production (tear production), incomplete eyelid closure (eyelid closure), excessive mucous secretions (mucous secretion) and decreased blink mechanism (blinking mechanism) have shown CVI higher than 0.80 in all psychometric criteria, we changed the title of this indicators as a result of experts' suggestions and recommendations, consequently accepted after being considered relevant by the consensus group.

Regarding the other constitutive definitions, operational and operational magnitude, the main recommendations suggested by the specialists and accepted by the consensus group were: to replace the term "Feeling" by "Sensation" in all NO; standardize the operational magnitudes of some indicators; remove from the indicators the expression "It is the name given" in the constitutive definitions, and remove terms from the indicator titles that represent operational magnitudes.

\section{DISCUSSION}

The use of content validation for the refinement of NOC indicators was the recommended action since the evaluations of specialists who have knowledge about nursing phenomena collaborate to strengthen the set of knowledge needed for nursing practice. Forming a consensus group has been another strategy used for the development of validation studies of NO. Another study aiming to validate NOs for the diagnosis "Impaired Tissue Integrity" used the consensus group technique as a strategy for validation ${ }^{(13)}$.

Regarding the Tear production indicator, it has significant relevance because the tear film is responsible for maintaining the health and function of the ocular surface, in addition to providing corneal oxygenation and protection against infections. Changes in the tear film may occur due to deficiency in production or increased evaporation of tears ${ }^{(14)}$.

Eyelid closure, defined as resting the upper eyelid over the lower eyelid, represents one of the main indicators present in patients admitted to the ICU. This fact can often be a consequence of sedatives use and coma. Another review research identified 39 different risk factors for dry eye, predominating in the studies lagophthalmos (85.18\%) and use of sedatives $(70.37 \%)^{(15)}$. In a cohort study conducted with patients admitted to an ICU, $49.2 \%$ had their eyeballs exposed (lagophthalmos) ${ }^{(16)}$.

Regarding the sensation indicators (burning eye sensation, itchy eye sensation, gritty sensation on the entire ocular surface and foreign body sensation on the entire ocular surface), in another community-based study carried out in the African continent in patients with dry eye, the main symptoms of these individuals were burning/stinging sensation (48.3\%) and gritty sensation $(53.4 \%)^{(17)}$.

Regarding the itchy eye sensation, eyes exposure to different environments such as sitting next to fans, using air conditioning, low humidity, and making visual efforts such as prolonged readings, exposure to cell phones, and computers, can condition this indicator. Furthermore, this sensation can be reported in patients admitted to the ICU due to their exposure to low temperatures and humidity, typical of this environment ${ }^{(18)}$.

According to the Localized foreign body sensation indicator, a study pointed out its presence in patients with dry eye syndrome due to the mechanical interaction between the palpebral conjunctiva and the surface of the cornea with deficiency of tear production. The main symptom reported by patients was constant discomfort affecting their activities of daily living ${ }^{(19)}$.

The Redness of the conjunctiva indicator refers to the extension of blood vessels on the ocular surface resulting from irritation or reduction in the amount of tear that can cause severe damage to the eye. In a study with patients with the nursing diagnosis Risk of dry eye, the Redness of the conjunctiva indicator was present in $59.7 \%$ of the sample ${ }^{(2)}$.

Regarding the Eye pain indicator, it is possible to understand it as a subjective experience that can be associated with real or potential damage to tissues, specifically in the eyes. Although ocular pain has been suggested as an essential factor in dry eye, the characterization of this type of pain and its relationship with traditional dry eye symptoms have not yet been systematically described in the literature. A study that aimed to assess whether the prevalence, severity, and quality of eye pain are associated with the severity of symptoms traditionally linked to dry eye revealed that, of the patients who showed mild to severe dry eye symptoms, $86.8 \%$ also reported ocular pain (pain intensity 3.86 \pm 2.35 ). The use of the visual analog scale is a one-dimensional instrument for assessing pain intensity and can be used by nurses to measure the eye pain indicator. The scale allows the patient to evaluate and mark the pain felt at that moment ${ }^{(20)}$.

The indicator Excessive watering is characterized as the apparent excess of tear production by reflex tearing, evidenced by a large volume of tears ${ }^{(21)}$. A randomized clinical study that used the Schirmer and Rose Bengal tests obtained the indicator of Excessive watering as one of the main findings in patients with dry eye ${ }^{(22)}$.

The Blurred vision indicator refers to to the symptom of blurred or blurry vision throughout the day. A study points out that prolonged exposure throughout the day to factors such as brightness and permanent air conditioning in the ICU trigger changes in the tear film that favors the appearance of blurred vision $^{(18)}$. Another study corroborates these results by inferring that such factors are capable of altering the maintenance of the 
integrity of the ocular surface and generating potential health problems $^{(19)}$.

Regarding the mucous secretion indicator, the increase in the activity of the conjunctival goblet glands triggers the excessive production of secretion, which emerges with a whitish color and little abundance. Cross-sectional research conducted in Brazil described that mucous secretion is an essential clinical data for the evaluation of patients admitted to the ICU for helping to predict ocular dryness ${ }^{(3)}$.

Regarding the Sensitivity to light indicator, the literature describes that prolonged exposure to light may be related to impairment or reduction in the frequency of blinking, as such exposure decreases the lubrication of eyes. Consequently, patients undergoing prolonged exposure to light can trigger dry eye sensitivity caused by inefficient tear lubrication (23-24).

The Eyestrain indicator consists of inadequate visualization of objects at the end of the day caused by strain on the visual system. Other studies also report eyestrain as one of the frequent symptoms in patients with dry eye $\mathrm{e}^{(11,25)}$. We highlight that this indicator was included in the NO Dry Eye Severity from a previous concept analysis study ${ }^{(11)}$.

The blinking mechanism indicator refers to the opening and closing movements of the eyelid. The proposal to include this indicator in this study also occurred after a concept analysis proposed to identify the indicators for the NO Dry Eye Severity in patients admitted to ICU ${ }^{(11)}$. Another study developed in patients with the nursing diagnosis Risk of ocular dryness pointed out that individuals with spontaneous blink reflex greater than five times per minute have a $40 \%$ lower risk of having dry eye than patients with an absent or reduced reflex ${ }^{(3)}$.

\section{Study Limitations}

This study is limited by the adopted design, in which the consensus group consisted of nurses linked to a single institutional context. Despite being, for the most part, knowledgeable in nursing taxonomies, they had little clinical experience, which may have made it difficult to understand the complexity of the scenario of this research.

\section{Contributions to nursing, health, or public policy fields}

This study contributes to the refinement of the indicators of NO Severity of the Dry Eye of the NOC aiming to provide nurses in clinical practice with the possibility of evaluating human responses, establishing more accurate results and indicators and being able, in this sense, to outline nursing interventions to maintain and improve patients' eye health conditions. It also contributes to the practice of nursing education by enabling the development of the science of nursing with the improvement of taxonomies, specifically the NOC.

\section{CONCLUSION}

This study carried out the content validation of the indicators of NO Severity of the Dry Eye. Of the 14 validated indicators, 12 belong to the NOC taxonomy, and two were identified in a previous study. We found that the indicators were considered mostly clear, simple, intelligible, relevant, accurate, formed by consistent expressions, and considered sufficient to measure Dry Eye Severity in patients admitted to the ICU. Although some have a cut-off point below 0.80 in some psychometric criteria, they could not be excluded because they were not statistically significant in the binomial test.

The refinement of the result continued in the consensus group, which allowed improving the indicators with regard to the description, as well as the constitutive definitions, operational and operational magnitudes, thus allowing greater clarity, accuracy, simplicity, objectivity, and relevance for future readers.

Thus, the validation of studies focused on NOC indicators provides taxonomy improvement and assists nurses in assessing and measuring the patient's health status. It also helps the professional to be able to identify the effectiveness and quality of nursing interventions in order to maintain or change the planning of the patient care plan.

\section{REFERENCES}

1. Craig JP, Nichols KK, Caffery B, Dua HS, Joo CK, Liu Z, et al. TFOS DEWS II Definition and Classification Report. Ocul Surf. 2017;15(3):276-83. doi: 10.1016/j.jtos.2017.05.008

2. Soares RPS, Fernandes APNL, Botarelli FR, Araújo JNM, Olímpio JA, Vitor AF. Clinical indicators of dry eye severity nursing outcome in intensive care unit. Rev Latino-Am Enfermagem. 2017;27;e3201. doi: 10.1590/1518-8345.2983.3201

3. Araújo JNM, Botarelli FR, Fernandes APNL, Oliveria-Kumakura ARS, Ferreira Jr MA, Vitor AF. Predictive clinical factors for ocular dryness in patients admitted to the Intensive Care Unit. Rev esc Enferm USP. 2019;53;e03493. doi: 10.1590/s1980-220×2018036603493

4. Stapleton F, Alves M, Bunya VY, Jalberty I, Lekhanont K, Malet F et al. TFOS DEWS II Epidemiology Report. Ocular Surface. 2017;15(3):334365. doi: $10.1016 /$ j.jtos.2017.05.003

5. Carvalho EC, Oliveira-Kumakura ARS, Morais SCRV. Clinical reasoning in nursing: teaching strategies and assessment tools. Rev Bras Enferm. 2017;70(3):662-8. doi: 10.1590/0034-7167-2016-0509

6. Moorhead S, Johnson M, Maas M, Swanson E. Nursing Outcome Classification (NOC). 6 ed. Missouri: Elsevier; 2018.

7. Medeiros RKS, Ferreira Jr MA, Pinto DPSR, Vitor AF, Santos VEU, Barichello E. Modelo de validación de contenido de Pasquali en las investigaciones en Enfermería. Rev Enferm Ref. 2015;4(4):127-35. doi: 10.12707/RIV14009

8. Lopes MVO, Silva VM, Araújo T L. Validação de diagnósticos de enfermagem: desafios e alternativas. Rev Bras Enferm [Internet]. 2013[cited 2019 Jun 20];66(5):649-655. Available from: https://www.scielo.br/pdf/reben/v66n5/02.pdf 
9. Lopes MVO, Silva VM. Métodos avançados de validação de diagnósticos de enfermagem. In: Heather HT (Org.). Pronanda. Ciclo 4. Artmed Panamericana; 2016.

10. Silveira DDS, Colomé BCL, Heck WT, Fernandes MNS, Viero V. Grupo focal y análisis de contenido en investigación cualitativa. Index Enferm. 2015;24(1-2):71-5. doi: 10.4321/S1132-12962015000100016

11. Fernandes APNL, Araújo JNM, Botarelli FR, Pitombeira DO, Ferreira Jr MA, Vitor AF. Dry Eye Syndrome in Intensive Care Units: a concept analysis. Rev Bras Enferm. 2018;71(3):1162-9. doi: 10.1590/0034-7167-2016-0582

12. Souza AC, Alexandre NMC, Guirardello EB. Psychometric properties in instruments evaluation of reliability and validity. Epidemiol Serv Saúde. 2017;26(3):649-59. doi: 10.5123/s1679-49742017000300022

13. Barreto LNM, Swanson LA, Almeida MA. Nursing outcomes for the diagnosis impaired tissue integrity (00044) in adults with pressure ulcer. Intern J Nurs Know. 2016;27(2):104-10. doi: 10.12707/RIV14009

14. Bron AJ, Paiva CS, Chauhan SK, Bonini S, Gabison EE, Jain S et al. TFOS DEWS II pathophysiology report. Ocul Surf. 2017;15(3):438-510p. doi: 10.1016/j.jtos

15. Araújo DD, Ribeiro NS, Silva PMA, Macieira TGRM, Silva PLN, Chianca TCM. Dry eye in critically ill patients: integrative review. Rev Pesqui: Cuid Fundam. 2017;9(4):907-16. doi: 10.9789/2175-5361.2017.v9i4

16. Araújo DD, Almeida NG, Silva PMA, Ribeiro NS, Werli-Alvarenga A, Chianca TCM. Prediction of risk and incidence of dry eye in critical patients. Rev Latino-Am Enfermagem. 2016;24:e2689. doi: 10.1590/1518-8345.0897.2689

17. Olaniyan SI, Oluyemi F, Bekibele CO, Ogundipea AO. Dry eye disease in an adult population in South-West Nigeria. Cont Lens Anterior Eye. 2016;39(5):359-64. doi: 10.1016/j.clae.2016.06.008

18. Akpek EK, Amescua G, Farid M, Garcia-Ferrer FJ, Lin A, Rhee MK, et al. Dry Eye Syndrome Preferred Practice Pattern ${ }^{\circledR}$. Ophthalmology. 2019;126(1):P286-P334. doi: 10.1016/j.ophtha.2018.10.023

19. Brissette AR, Drinkwater OJ, Bohm KJ, Starr CE. The utility of a normal tear osmolarity test in patients presenting with dry eye disease like symptoms: A prospective analysis. Cont Lens Anterior Eye, 2018;42(2):185-189. doi: 10.1016/j.clae.2018.09.002

20. Felix E, Zlotcavitch L, Levitt R, Sarantopoulos K, Patin D, Galor A. Ocular pain is associated with dry eye symptoms. T J Pain. 2015;16(4):12. doi: 10.1016/j.jpain.2015.01.061

21. Horng CT, Chou HL, Tsai KL, Hsiao HY, Lin SY, Huang SF, et al. The observation for ocular surface diseases in respiratory care center in regional teaching hospital in Southern Taiwan. Life Sci J [Internet]. 2014[cited 2019 Jun 11];11(6):672-9. Available from: http://www.lifesciencesite. com/Isj/life1106/102_A00292life110614_672_679.pdf

22. Capita L, Chalita MR, Santos-Neto LL. Prospective evaluation of hypromellose $2 \%$ for punctal occlusion in patients with dry eye. Cornea. 2015;34(2):188-92. doi: 10.1097/ICO.0000000000000325

23. França CFSM, Fernandes APNL, Carvalho DSRP, Xavier SSM, Ferreira Jr MA, Vitor AF. Evidence of interventions for the risk of dry eye in critically ill patients: an integrative review. App Nurs Res. 2016;e14-17. doi: 10.1016/j.apnr.2015.05.016

24. Zeev MS, Miller D, Latkany R. Diagnosis of dry eye disease and emerging Technologies. Clin Ophthal. 2014;8:581-590. doi: 10.2147/OPTH. S45444

25. Uchino M, Kawashima M, Uchino Y, Suzuki N, Mitamura H, Mizuno M, et al. The evaluation of dry eye mobile apps for screening of dry eye disease and educational tear event in Japan. Ocul Surf. 2018;16(4):430-435. doi: 10.1016/j.jtos.2018.06.002 